\title{
El costoso engaño del cambio climático y el calentamiento global
}

\author{
Eduardo Badía Serra ${ }^{1}$ \\ Recibido en febrero 2016, aceptado en abril de 2016
}

\begin{abstract}
Resumen
El presente escrito plantea el costo de afrontar medidas tendientes a disminuir las consecuencias del cambio climático de que hablan los países de cuantioso poder económico. Partiendo de las posturas antropocentristas que hicieron de la naturaleza un objeto de abuso, el autor recorre las propuestas del pensamiento antrópico, Penrose y las ideas homocentristas, para decantar en la historia de la tierra y en el cambio climático. Poniendo al descubierto la falsedad de los numerosos anuncios catastróficos de los 'grupos de científicos', propone ocuparse de los verdaderos problemas, como la degradación ambiental y la vulnerabilidad ante la naturaleza de la sociedad humana.
\end{abstract}

Palabras claves:

Cambio climático, antropocentrismo, Penrose, degradación ambiental, vulnerabilidad.

\begin{abstract}
:
This letter raises the cost of addressing measures to reduce the consequences of climate change speaking countries of substantial economic power. Based on the anthropocentric attitudes that made nature an object of abuse, the author covers the proposals of anthropic thinking, Penrose and homocentristas ideas, to decant in the history of the earth and climate change. Exposing the falsity of the many catastrophic announcements of the ' groups of scientists ' proposes to deal with real problems, such as environmental degradation and vulnerability to the nature of human society.
\end{abstract}

1. Ingeniero Químico, Instituto Americano de Ingenieros Químicos, New York, USA, 1992. Doctor en Química Industrial, Universidad de El Salvador, El Salvador, 1966. Licenciado en Filosofía, Universidad Centroamericana José Simeón Cañas, El Salvador, 1990. Doctor Honoris Causa en Educación, Universidad Tecnológica de El Salvador, 2005. Es Investigador independiente.

E-mail: ebbserra@yahoo.com.mx 


\begin{abstract}
Keywords:
Climate change, anthropocentrism, Penrose, environmental degradation, vulnerability.
\end{abstract}

\title{
I. El hombre, su papel en el cosmos
}

Para poder comprender por qué el hombre se encuentra ahora tratando de luchar tan denodadamente contra el cambio climático, pretendiendo que es por sus acciones que este cambio se está dando, si es que se está dando, y asumiendo incluso la responsabilidad de corregir el curso de la naturaleza y modificar su dinámica, es necesario que hablemos un poco de quién es, precisamente, este ser que llamamos "Hombre", ese a quien alguna vez Martín Heidegger dijera que es "el ser que tiene más ser", en una muestra de antropocentrismo desmedido.

Hablemos previamente de ello:

\section{1) El Antropocentrismo}

El hombre es la medida de todas las cosas, de las que son en tanto que son,y de las que no son en tanto que no son. Protágoras de Abdera, 491 a.C.

PLa Real Academia Española de la Lengua define el Antropocentrismo como una "doctrina o teoría filosófica que supone que el hombre es el centro de todas las cosas, el fin absoluto de la naturaleza y punto de referencia de todas las cosas: El antropocentrismo se opone al teocentrismo". Tal definición debe verse desde diferentes planos. Epistemológicamente sitúa al hombre como medida de todas las cosas. Ya Protágoras, el sofista de Abderá, lo había situado así hace unos 25 siglos, cuando florecía la filosofía en Atenas y el mismo Sócrates había relegado a segundo plano el pensamiento físico-cosmológico-metafísico de los anteriores filósofos, para colocar precisamente al hombre en el primero. No es el antropocentrismo, pues, nada nuevo en la historia del pensamiento. Hay también una dimensión ética en el concepto, pues si el hombre está al centro de todas las cosas, sus intereses serán entonces aquellos que deberán recibir la mayor, si no la única, atención, y el juicio humano será la única medida con la cual deberán considerarse los demás seres y el conjunto de la naturaleza. Ontológicamente, entonces, todo se subordina al ser humano.

Históricamente, el antropocentrismo se va situando de diferentes maneras y con diferentes ponderaciones en la evolución de la cultura. Si bien se sabe reconocer su aparición en el rompimiento de la visión teocentrista que había predominado de manera general durante todo el medievo, y que se sabe ubicar 
en el renacimiento, esto no es del todo preciso ni exacto. Como dice Gerardo Anaya Duarte, S. J., (Gerardo Anaya Duarte, S. J., Antropocentrismo, ¿un concepto equívoco?, Entretextos, 17, Universidad Iberoamericana, León, 2014), "indudablemente que las cosmovisiones medievales ponen como centro a Dios, pero no forzosamente minusvalorando al ser humano". Cita Anaya Duarte el texto de Sn Gregorio de Nisa, padre de la Iglesia, (335-394): “Después de haber terminado la creación del hombre, -que era totalmente nuevo y totalmente hermoso-, Dios le dijo: 'Hombre, tú serás el señor de la tierra y superior a todo lo que existe en el universo. Serás igual a mi, tu Dios. Como prueba de tu semejanza con Dios, te doy desde ahora la prerrogativa por excelencia: La libertad"'. Es decir, en pleno medievo, ciertamente bajo una visión teocéntrica fundamental, el hombre era desde ya un ser relevante.

El historiador francés J. Michelet sintetizó en la fórmula “Descubrimiento del mundo, descubrimiento del hombre", la innovación dada en los siglos XV y XVI cuando por primera vez se utilizó la palabra "Renacimiento" para expresar el concepto de una época. Según la típica fórmula del siglo XV, "los estudios humanísticos se llaman así porque llevan al hombre a la perfección”. Es, el Renacimiento, el efecto de un humanismo que redescubre la autonomía del hombre, y lo hace artífice de su propio destino, rompiendo con la visión medieval que considera la naturaleza humana finita e inmersa en el pecado, constantemente necesitada de recurrir al Dios cristiano trascendente para explicar no sólo su existencia sino su modo de relacionarse con el mundo y con la sociedad. Conducen a ello de alguna manera el redescubrimiento y la imitación de los clásicos griegos y latinos, tanto en la literatura como en el arte. Aparecen así las explicaciones del cosmos y de la realidad social por medio de la sola fuerza del hombre. Hay una concepción naturalista del mundo a partir de la renovación humana del pensamiento griego.

Esta posición de sostener el predominio del hombre sobre todo lo que le rodea se rompe con la llegada del pensamiento moderno en el siglo XVII, con lo que se ha dado en llamar Filosofía Moderna. Aquí, los grandes temas anteriores, el cosmos, Dios, el hombre, ceden ante el nuevo paradigma, el conocimiento, que cederá también contemporáneamente ante el nuevo enfoque filosófico que tiende hacia la realidad, sobre la base de una diferente visión filosófica y científica. Efectivamente, el antropocentrismo parece ahora entonces ser no otra cosa que una idea ingenua ante la realidad. Por supuesto que pensar aun que el hombre es el centro del mundo y del cosmos, es algo que de ingenuo pudiera considerarse sesgado. La posición de que sólo los seres humanos deben ser objeto de consideración moral, y que sus intereses deben colocarse por encima de los del resto de seres que conforman la naturaleza, no es admisible. Sin embargo, aun hoy en la actualidad, se sostienen posiciones que corren en tal sentido, sobre todo en algunos ámbitos que se dicen, contradictoriamente, defensores de la naturaleza y del ambiente, ámbitos que precisamente niega o desprecia la visión del hombre como centro de todas las cosas. 
Y es que el hombre es un ser pequeño en todas las dimensiones en que pudiera ser considerado. Veamos algunas realidades que la ciencia y la filosofía nos van mostrando sobre la dimensión del hombre:

La vida no es una condición propia de los seres humanos. La vida es una realidad cósmica que trasciende la sola condición humana. El ser humano para nada tiene la menor consideración ante la posibilidad de que la vida sea uno de sus efectos. Ni siquiera es posible ya considerar que el hombre es, hoy por hoy, el culmen de la evolución, por el solo hecho de poseer esa facultad que llaman “inteligencia” y que le atribuyen exclusivamente a él. "No hay genes de la inteligencia”, ha demostrado la ciencia, y con ello, la evolución, ontogenética y filogenética, no es una función de dicha facultad. El cosmos, y la Tierra dentro de él o como parte de él, funciona y razona de muy diferente manera: Para que haya vida en la Tierra, la gravedad debe ser la que es, y no mayor ni menor; hay vida en la Tierra por la baja excentricidad, cercana a lo circular, que esta tiene, excentricidad que si fuera mayor no permitiría tal vida; hay vida en la Tierra porque su eje de rotación está inclinado; hay vida en la Tierra porque su tiempo de rotación es pequeño, sólo 24 horas, y no tan grande como 240 horas; hay vida en la Tierra porque sólo el 25 \% de ella es tierra firme y no agua, lo cual, de ser mayor, negaría tal vida; hay vida en la Tierra por la existencia del vapor de agua en una muy alta proporción, y sólo una muy baja proporción de anhídrido carbónico. Además, es necesario para que haya vida en la Tierra que esta posea actividad volcánica, vulcanismo, para producir gas carbónico. $Y$ también que tenga el tamaño suficiente para que la gravedad permita que su atmósfera no se evapore y que los seres vivos puedan desarrollarse. Hace falta que exista agua en estado líquido para que haya vida en la Tierra. ¿Qué papel juega el hombre en todo lo anterior, si es que juega alguno?

Y no sólo son necesarias las anteriores condiciones “locales” para que haya vida en la Tierra. La Tierra no se encuentra aislada del cosmos. Hay vida en la Tierra porque hay una estrella próxima, el Sol, que le suministra energía, y además, porque esta estrella se encuentra adecuadamente localizada, ni demasiado lejos para que no pueda calentarla, ni demasiado cerca para que pudiera quemarla. Y para que haya vida en la Tierra hace falta también un satélite que estabilice al planeta, en esta caso, la Luna; sin la Luna, el eje de rotación de la Tierra podría oscilar de vez en cuando debido a la atracción de los demás planetas, lo cual modificaría el clima y crearía condiciones incompatibles con la vida. La vida en la Tierra exige que se dé la química del carbono en el cosmos, sobre todo en las estrellas. $Y$ en esto, ¿Cómo entra el hombre?

Cuando comprobamos la redundancia de la naturaleza traducida en la enorme cantidad de especies existentes, (actualmente se estiman 5 millones de especies animales, y cada día se descubre una nueva), y la variedad de dichas especies, como lo prueban los fósiles descubiertos, se debe concluir que la naturaleza ha explorado ya todas las soluciones, incluso las más extravagantes, y ha hecho 
todo lo que tenía que hacer. Se calcula que a lo largo de la evolución han desaparecido quinientos millones de especies. ¿Es sana, entonces, y conducente, esa preocupación humana, inmensa y desesperada, que actualmente se tiene sobre el proteger las “especies en peligro de extinción”? ¿lgnorancia, sencillez, malicia? Se calcula que hay en la naturaleza un poco más de un millón de especies de insectos, seres sexualmente muy activos y además muy resistentes. $Y$ hay que decir que el poder de multiplicación de los insectos es sólo minúsculo comparado con el de las bacterias. Hay opiniones que corren en el sentido que son estos insectos los que han de sustituir al hombre en la escala evolutiva. ¿El hombre, el único animal inteligente?

Ante tales realidades, y sólo se han citado muy pocas, se demuestra y pone en evidencia el tosco, anacrónico y desmedido homocentrismo actual, que ignora que la naturaleza es más que el hombre, y que dentro de ella, el hombre es un minúsculo elemento incapaz de modificarla, y menos aun de corregir su dinámica, la dinámica terrestre y universal. El célebre principio del sofista de Abderá es ahora negado por la realidad misma, e insistir en su validez puede llevar a la naturaleza, y al hombre con ella, a lamentables situaciones.

Cabe, y es urgente la pregunta: ¿La existencia del hombre da sentido al universo, (principio antrópico), o la existencia del universo da sentido al hombre??

\section{2) El Principio Antrópico}

Les mostró sus maravillas para que se fijaran en ellas.

Ecli.17.8

Digamos algunas cosas sobre el Principio Antrópico.

No es nuevo este concepto del Principio Antrópico. El mismo principio del relativismo radical de Protágoras podría considerarse una expresión del Principio Antrópico. La expresión de Teilhard de Chardin de que "el hombre es el producto supremo y necesario de la evolución, el que da sentido al fenómeno general de la vida sobre la Tierra", es una expresión del Principio Antrópico. La vida sólo tiene sentido si avanza hacia el hombre, afirmaba el filósofo y teólogo jesuita, tratando de conciliar evolución y creación, en una expresión de radical antropomorfismo. La filosofía ha gastado muchas horas de reflexión sobre ello. Pero la ciencia, coincidiendo en esencia con la posición filosófica, hace de tal principio una expresión diferente. Voy a referirme a ello utilizando la expresión que del mismo hace el físico y matemático inglés Roger Penrose.

El universo se origina, dice Penrose en "La mente nueva del Emperador", (Roger Penrose, La mente nueva del Emperador, Consejo Nacional de Ciencia 
y Tecnología, Fondo de Cultura Económica, México, 1996), a partir de un gas difuso del cual se condensaron las estrellas, y que fue literalmente "escupido" según la teoría estándar, como consecuencia de la gran explosión, el Big Bang. Sin embargo, no fue esa una explosión ordinaria en la que el material se expele a partir de un punto central hacia el espacio preexistente. Aquí, el propio espacio es "creado" en la explosión, y no existe ni existió punto central. No hay, entonces, "espacio vacío preexistente" en el cual se vacíe la materia producida por la explosión; el mismo espacio, es decir, la superficie del globo, nace de la explosión. Con ello, agrega, no hay porqué considerar que la conciencia necesariamente provenga o se origine en la selección natural, pues bien esta conciencia, que aparece en el hombre, pudo haber sido producto de dicha gran explosión, producto de la Creación en un solo acto único y unitario.

¿Qué importancia tiene la conciencia para un universo en su totalidad? ¿Podría existir un universo sin habitantes conscientes? ¿Están las leyes de la física especialmente diseñadas para permitir la existencia de vida consciente? ¿Hay algo especial en nuestra localización particular en el universo, ya sea en el espacio o en el tiempo? Estas son las preguntas claves que se hace el Principio Antrópico, que en su expresión llamada “débil” se refiere a la localización espacio-temporal de la vida consciente o inteligente. El Principio antrópico en su forma "fuerte" va aún más lejos, pues no sólo se interesa en nuestra localización espacio-temporal dentro del universo sino de una infinidad de universos posibles. En opinión de Penrose, este "Principio Antrópico Fuerte" tiene un carácter algo dudoso, y los físicos tienden a invocarlo cuando no tienen una teoría lo bastante buena para explicar los hechos observados. El "Principio Antrópico Débil” al contrario, le parece incuestionable, siempre que se utilice cuidadosamente. El Principio Antrópico, en cualquiera de sus expresiones, sostiene que la conciencia es inevitable en virtud del hecho de que tendría que haber seres sensibles para observar el mundo, lo cual implica que no es necesario suponer que la sensibilidad tenga alguna ventaja selectiva. Claro que esos "seres sensibles" observadores del mundo somos nosotros, los hombres, y en la expresión "débil", se puede establecer una razón para que la conciencia exista sin que tenga que ser favorecida por la selección natural. Sin embargo, Penrose no cree que sea el Principio Antrópico la razón auténtica, o al menos no la única razón, para la evolución de la conciencia. Para él hay suficientes pruebas procedentes de otras direcciones para convencerse de que la conciencia tiene una poderosa ventaja selectiva, y no cree que el Principio Antrópico sea necesario.

En esto del origen de la vida, en apoyo a esto último que hemos dicho apoyándonos en Penrose, hay muchas posiciones, opiniones y teorías. Robert Clarke, en su libro "Los nuevos enigmas del universo", (Robert Clarke, Los nuevos enigmas del universo, Alianza Editorial, El libro de bolsillo, segunda edición, España, 2015), señala cuando menos, las tres siguientes: a) Las primeras moléculas biológicas llegaron del espacio, y sembraron la Tierra bajo el impacto de meteoritos o cometas; b) Las primeras moléculas verdaderamente biológicas, como las que componen los ácidos nucleicos, son demasiado complejas para poder haber apa- 
recido de manera espontánea. Hubo una especie de vida mineral que precedió a la vida orgánica, y que pudo surgir en forma de cristales u otros compuestos minerales como las piritas, o bien en arcillas cuya arquitectura se asemeja a la de las grandes moléculas biológicas; después estas se emanciparon de su soporte mineral para hacerse autónomas; c) La vida pudo aparecer en el fondo de los océanos, y las extrañas bacterias que se ven hoy en esas fumarolas que salen a más de $100{ }^{\circ} \mathrm{C}$ de las profundidades del planeta, en las grietas situadas a más de 20,000 metros bajo la superficie marina, son los vestigios de lo que se denomina "arqueobacterias", los ancestros de todos los seres vivos. Schrodinger, en su importante libro “¿Qué es la vida?, (Erwin Schrodinger, ¿Qué es la Vida?, Canto, Cambridge University Press, UK, 2010), sostiene que la parte más esencial de una célula viva, la fibra cromosómica, está constituida por sus famosos “cristales aperiódicos", que son los portadores materiales de la vida. El "cristal aperiódico" es la estructura química del gen abstracto de la genética básica, la “molécula maravillosa”, y con él se moleculariza el gen de la genética clásica.

El mundo es asombroso, el universo lo es más. La física nos muestra que la flecha del tiempo tiende hacia el desorden; la termodinámica nos muestra que un sistema aislado tiende naturalmente hacia el desorden; los seres vivos se desorganizan envejeciendo. Es lo que llamamos "Entropía”. Sólo en nuestra galaxia hay más estrellas que seres humanos hayan existido jamás. Para contar las moléculas que existen en un centímetro cúbico de aire, a un ritmo de una molécula por segundo, haría falta diez veces más tiempo que el transcurrido desde el nacimiento de nuestro universo, hace más o menos 15,000 millones de años, lo cual significa que en un centímetro cúbico de aire, un espacio más o menos como el que ocupa un grano de maíz, hay unos cinco millones de millones de millones de moléculas, 5 x 1018 moléculas. Y tantas maravillas más que podríamos contar del universo y de la tierra. Por eso, bien dice la Escritura: “Les mostró sus maravillas para que se fijaran en ellas", (Ecli.17.8).

Podríamos expresar el Principio Antrópico diciendo, como dicen Hawking-Mlodinov en "The Grand Design", (Stephen Hawking-Leonard Mlodinov, The Grand Design, Bantam Books, New Yok, 2010): “Vivimos en una región del universo adaptada a hospedar formas de vida inteligente". Los defensores y propulsores del Cambio Climático y del Calentamiento Global sonríen alegres con tales expresiones, esta u otras, y confirman su antropomorfismo radical mostrándose superiores a la naturaleza y al cosmos mismo. Pero Hawking-Mlodinov definen luego lo que es el universo y lo que es el hombre: "El universo - dicen-, es una 'hidrógeno-forma de vida'; el hombre es una 'carbón-forma de vida' ”, con lo cual quitan al hombre del centro de todo, y dejan en este a la naturaleza. ¿A qué viene entonces esa pretensión del hombre de considerarse el centro de todo el cosmos, y de querer dominar a la naturaleza, corregir su rumbo, y pretender que con sus actos, este se está alterando negativamente? 
Volvamos a algunas cuestiones fundamentales que, luego de este corto recorrido, merecen considerarse de nuevo:

¿Es el hombre, la medida de todas las cosas, de las que son en tanto que son, y de la que no son en tanto que no son?

¿Es el hombre, el centro de todas las cosas, el fin absoluto de la naturaleza y punto de referencia de todas las cosas?

¿Es la existencia del hombre lo que da sentido al universo?

\section{3) El Hombre}

El Hombre: Animal de realidades.

Las anteriores preguntas se bastan con un "sí" o con un "no". No requieren de una mayor o más detallada explicación.

El Universo, siguiendo la versión estándar del "big bang", se formó hace unos 15,000 millones de años, a partir de la "gran explosión” de cuya existencia, antes del tiempo y del espacio de Planck, $1.33 \times 10^{-43}$ segundos y $4.23 \times 10-33$ centímetros, nadie, ni la ciencia, sabe nada. La Tierra se formó hace unos 4,600 millones de años, como una masa viscosa y confusa en donde nada podía ser. La vida en la Tierra aparece hace unos 3,000 millones de años, con la presencia de organismos muy simples, y luego, con el surgimiento evolutivo de peces, anfibios, reptiles, aves y mamíferos. Aparecen los primates, seres prehumanos, hace 65 millones de años; y luego los simios, primates no humanos, gorila, chimpancé, orangután y bonobo, hace unos 10 millones de años; y los homínidos, familia de primates que luego evolucionan hacia el género humano, hace 6 millones de años, cuyo primer exponente fue el Australopitecus, con un cerebro ya de 400 centímetros cúbicos.

El género “Homo", aparece entonces hace 2.4 millones de años. Su cerebro va evolucionando desde los iniciales 400 centímetros cúbicos a luego 700 centímetros cúbicos en este "homo", y hasta los 1,400 y 1,700 centímetros cúbicos del "Homo Sapiens". Se dice que el hombre es un mono con cerebro grande, y se reconocen seis especies: Homo habilis, 1.9 millones de años de edad, homo ergaster, homo erectus, 1.8 millones de años de edad, homo heidelbergensis, 600,000 a 800,000 años de edad, homo sapiens, Neanderthal y Cro Magnon, 40,000 a 200,000 años de edad, y homo sapiens sapiens, este último, el hombre actual, 40,000 a 50,000 años de edad, ese que se dice ser la medida de todas las cosas, el fin absoluto de la naturaleza, el punto de referencia de todo, aquel, pues, que da sentido al universo. 
Si consideramos que los elementos esenciales que caracterizan a las civilizaciones son principalmente el sedentarismo y el uso de la escritura, lo cual podemos colocar en Sumeria, Mesopotamia, hace 5,500 años, puede deducirse que el ser humano ha vivido 2,294,500 años, el $99.77 \%$ de su historia, en condición de salvajismo y barbarie, y sólo un $2.3 \%$ en condición civilizada. Esto quiere decir, como afirma Badía, (Roberto Badía Montalvo, Civilizaciones e Imperios de la Antigüedad, la Hélade y la Antigua Grecia, en prensa), que en su cerebro, en donde reside la capacidad cognitiva, los sentimientos, pensamientos, emociones, memoria e inteligencia, existen entre 80 y 100,000 millones de neuronas que guardan tanto memorias de la vida del hombre salvaje y bárbaro, como del homo sapiens sapiens actual. Es decir, dice Badía, "el hombre actual lleva desde su nacimiento un 'paquete evolutivo' que es el determinante de su cultura y comportamiento, y en el que predominan mayoritariamente características del ADN del hombre salvaje y bárbaro". Este es, precisamente, el hombre que pretende ser la medida de todas las cosas, el punto de referencia de todo, aquél que da sentido al universo. Este es el que pretende torcer el rumbo de la naturaleza, modificando la dinámica universal, que le superan en experiencia y vida unos 5,000 millones de años. Faltaría al homo sapiens sapiens mucho por evolucionar para justificar tal pretensión, y hacer que en su composición neuronal predominen ya los elementos civilizatorios sobre los bárbaros y salvajes.

En el universo visible hay un átomo por cada metro cúbico, una Tierra por cada 10 años-luz ${ }^{3}$, una estrella por cada $10^{3}$ años-luz ${ }^{3}$, una galaxia por cada $10^{7}$ años-luz ${ }^{3}$, un universo por cada $10^{10}$ años-luz ${ }^{3}$. Luego, si el universo visible es el universo total, hay en él un universo, mil millones de galaxias, mil millones de millones de millones de estrellas. ¿Qué hace, aquí, el hombre? ¿Cuál es su papel?

Al homocentrismo, al hombre homocéntrico, le hace falta ahora una buena dosis de humildad, y otra muy buena de prudencia. Debe reconocer que el humilde sabe que no sabe, y que sólo el enfermo piensa que sabe lo que no sabe, como afirmaba el taoísmo. Estos omnipresentes y omnipotentes sabios deben volver por el sentido de la humildad, agachando la cabeza para entrar en el templo de la fe. Como decía Ludwing Winttgenstein, "de lo que no se puede hablar mejor es callarse". La prudencia debe alimentar al hombre con el sentido de la paciencia para esperar por un mayor grado evolutivo, reconociendo su pequeñez ante lo que no conoce. Dejar a la naturaleza actuar, no afectarla con su conducta, y menos aun tratar de corregirla y cambiar su dinámica, es la mejor forma de esperar y afrontar los cambios que en ella se dan. De todas formas, aunque como sabemos, la dinámica universal tiende entrópicamente hacia el desorden, al final, como producto de ello llegará al equilibrio, que es, precisamente, su muerte térmica. Para ello falta mucho. Según la teoría de Friedmann basada en un universo que se expande y se contrae continuamente, siguiendo la geometría esférica de Riemann, apenas nos encontramos a un tercio de la expansión actual, 15,000 millones de años, lo cual significa que para llegar al punto de 
inflexión faltan dos tercios más, 30,000 millones de años, y para llegar al final de la sucesiva contracción, el big crunch, faltarán entonces 75,000 millones de años. Las magnitudes universales, propias del espectro electromagnético, no son sujetos de la consideración humana, encerrada ésta en el insignificante espacio de su espectro visible, dentro del cual nada ocurre fuera de lo rojo y de lo violeta, con sus minúsculas longitudes de onda y energías.

El hombre, ha dicho Zubiri, es un “animal de realidades”, golpeando así las pretensiosas definiciones que del mismo habían dejado tantos años de reflexión filosófica, (la medida de todas las cosas de Protágoras, el animal racional aristotélico, la sustancia pensante cartesiana, el ser que tiene más ser de Heidegger, etc.), definiciones que se sitúan en un antropocentrismo claro y en mayor o menor medida absolutista. Zubiri le señala al hombre la necesidad de apropiarse de la realidad, no pretendiendo situarse en el centro de la realidad sino trascendiendo su animalidad para hacer del de-suyo, un suyo, pero en propio. Si efectivamente se reconoce tal realidad del hombre inmersa dentro de otra realidad natural inmensamente mayor, y aun de otra inconmensurablemente mayúscula que es la realidad universal, ¿Qué puede hacer el hombre, ese aun históricamente $99.77 \%$ ser salvaje y bárbaro, tratando de decirle a la naturaleza y al universo cómo debe comportarse y de qué forma debe modificar su ruta dinámica? ¿Es, ante tal realidad, conducente, pensar que son unos tales clorofluorocarbonos, o unos hidrógenofluorocarbonos, o un anhídrido carbónico, o unos metanos, o unos gases nitrosos, etc., los que están causando las modificaciones del clima, y no las otras funciones, enormemente mayores, que ya he señalado antes de manera general, y que se salen del espectro del dominio que la humanidad pudiera tener sobre ellas?

Ahora nos encontramos ante expectativas de presencia extraterrestre en la Tierra. Y ya el hombre, este homo sapiens sapiens $99.77 \%$ aun salvaje y bárbaro, ha anticipado la forma y el aspecto de estos seres imaginándolos como humanos, concibiéndolos como antropomorfos. Su aspecto, su forma, los sentidos que se les otorgan, cómo se desplazan, cómo ven, e incluso hasta cómo sienten, son formas casi idénticas a las de los humanos que habitan la Tierra. Es el homocentrismo, este extremado antropocentrismo, el que orienta tales visiones. La prudencia y la humildad le están ausentes al ser humano. Y eso le oculta, lamentablemente, la realidad, impidiéndole hacer de su de-suyo, un suyo.

No he hablado aun de otro de los aspectos que nublan a la especie humana, y que le presionan en el sentido de tratar de entrar a modificar el rumbo natural, enseñándole a la naturaleza cómo debe caminar y hacia dónde. Este aspecto, que luego enfocaré, es el que tiene que ver con los intereses económicos y los intereses de poder y dominación de unos hombres sobre otros, de unas sociedades sobre otras. Y es que este salvaje y bárbaro homo sapiens sapiens, se ha vuelto, como diría Hobbes, "el lobo de sí mismo", "el hombre es el lobo del hombre", en otra clara manifestación de homocentrismo que coloca a los 
animales, en este caso, el lobo, en un plano de franca inferioridad.

\section{El cambio climático y el calentamiento global}

Con continua frecuencia, algunos pueblos reciben mensajes que los llevan a modificar sus vidas y a orientar sus acciones hacia pseudoproblemas, que no sólo le distraen de lo que debieran ser sus verdaderas preocupaciones sino también le consumen recursos, económicos sobre todo, en su satisfacción. Son distractores que nublan la visión de la realidad, haciendo que esta se deje a un lado para ocuparse de situaciones aparentemente importantes que en el fondo no son más que estrategias del poder para seguir el curso de su dominación. Los pueblos que no tienen guías, líderes, que sepan aclarar tales situaciones, son fáciles de engañar, y asumen responsabilidades que no deben asumir, olvidándose de su propia razón vital.

Ejemplo de estos distractores y pseudoproblemas, son, precisamente, los llamados "cambio climático" y "calentamiento global". El mundo se encuentra gastado increíbles sumas de dinero, ocupando recursos y distrayendo esfuerzos para tratar de solucionar un problema que no le corresponde solucionar, y que aunque así fuera, no puede solucionar, debido a sus características, a sus causas y a su magnitud. En tanto, los problemas reales siguen sin solución, ocultos y disimulados.

No quiero decir que no pueda la Tierra estar enfrentando un nuevo cambio climático. Esto es normal, natural, dentro de su dinámica, y además, necesario para mantener su equilibrio. Lo que quiero decir es que el hombre ha asumido una responsabilidad que no le corresponde asumir, porque en primer lugar no es una causa real del mismo, y en segundo lugar, porque aunque así fuera, no dispone de las herramientas precisas y suficientes para su solución. Mientras interpreta equivocadamente un problema cuyas causas se encuentran muy lejos de sus posibilidades, ignora otros que no sólo descuida sino acelera, tales, la deforestación, la contaminación y el asolvamiento de su ambiente local, por ejemplo.

En cuanto al llamado "calentamiento global”, las consideraciones son aún más críticas, como trataré de exponer posteriormente.

Deseo hablar entonces un poco acerca de lo que ahora se comenta como "cambio climático":

\section{La historia de la tierra}

La “vieja” “Nueva Enciclopedia Autodidáctica Quillet”, (Arístides Quillet, Nueva Enciclopedia Autodidáctica Quillet, tomo III, México, 1968), hablando del hombre y de su posición en la Tierra, dice que "Sería un error creer que el período geológico en que vivimos va a ser el último. A este seguirán de seguro, 
muchos otros, después de haber durado millares de siglos como los que nos han precedido. El paso del hombre por la superficie del globo no es, sin duda, sino una fase de la evolución de los seres vivos, y en los tiempos venideros nuestra raza desaparecerá o será sustituida por sus descendientes, considerablemente modificados, de igual modo que los animales que hoy pueblan nuestro mundo son los descendientes de otras especies que fueron otro tiempo prósperas, que hoy están extinguidas y en las que sólo la mirada del sabio es capaz de encontrar un parentesco con las especies actuales".

Hay mucha sabiduría en la afirmación anterior. Hay en ella una adecuada comprensión del hombre y de su papel en la historia universal y en la historia de la Tierra. La historia de la Tierra nos comprueba tajantemente lo que decimos. Ha habido a lo largo de ella, cambios asombrosos que han afectado la vida de los seres vivos y de los seres inanimados. Pero la historia ha seguido, y estamos lejos de pensar que la actual expresión del cambio climático pueda producir situaciones cataclísmicas que puedan llevar a la destrucción inmediata de la vida y de la naturaleza, como a menudo pronostican los propulsores actuales del cambio climático y del calentamiento global.

A lo largo de la historia geológica del planeta ha habido cambios climáticos numerosos y de notable magnitud, tanto por causas naturales externas, (cambios en la constante solar, ciclos de los parámetros orbitales, impactos de meteoritos, etc.), como por causas naturales endógenas, (variación en la actividad volcánica, desplazamientos de los continentes, deriva continental, composición atmosférica, corrientes oceánicas, el campo magnético terrestre, los efectos antropogénicos, etc.), como ya se ha dicho. La información y los datos de tales procesos están aun lejos de posibilitar conclusiones definitivas: La brevedad de las series meteorológicas instrumentales para el análisis de las variaciones climáticas y de las tendencias climáticas obliga al uso de datos proximales, por ejemplo, el que la temperatura media global ha aumentado $0.74{ }^{\circ} \mathrm{C}$ durante el último siglo, (1906-2005), siendo los últimos doce años de dicho período, los más cálidos, (J. Martin Vide, El sistema climatic y deu afirmacions sobre el camvi climatic, Cátedra Lluis A. Santaló, UdeG, 10 de abril de 2008). La percepción climática difiere a menudo de la realidad climática, por lo que los presuntos cambios climáticos percibidos casi nunca tienen el aval de los registros instrumentales. Los humanos sabemos comportarnos no tal como es la realidad sino cómo la percibimos.

Se sabe considerar la historia climática prehistórica con no tan buena precisión, (datos reducidos y modelos de predicción futura y pasada), y la historia climática "reciente", sólo relativamente precisa. Veamos un poco cómo ha sido esa historia, y utilizo un documento de Wikipedia por considerarlo suficiente y de naturaleza y uso libre, evitando así las susceptibilidades en que suelen entrar los propietarios de los “derechos reservados" que amparan algunas fuentes: 
(Wikipedia, Cambio climático, http://es.wikipedia.org/wiki/Cambio_clim\%C3 \%Altico, 20/10/2011:

"En los primeros momentos de la existencia de la Tierra, el Sol emitía sólo el $70 \%$ de la energía actual y la temperatura de equilibrio era de $-41^{\circ} \mathrm{C}$. Existían los océanos, y la vida desde hace unos 3,800 millones de años. Esta llamada "Paradoja del Sol Débil" sólo se explica por una atmósfera con mucha mayor concentración de $\mathrm{CO}_{2}$ y un efecto invernadero más grande.

En el proterozoico, una disminución importante en los niveles de $\mathrm{CO}_{2}$ atmosférico condujo a los episodios conocidos como "Tierra bola de nieve".

En el pérmico-triásico, aumentos importantes en el $\mathrm{CO}_{2}$ condujeron a un período de extinción masiva que provocó calentamientos excesivos del agua del mar, emisión del Metano atrapado en los depósitos de hidratos de metano que se encontraban en los fondos marinos, acelerando el proceso de calentamiento hasta llevar a la Tierra a la peor extinción en masa que ha padecido.

Actualmente, los bosques tropicales ocupan la región ecuatorial del planeta y entre el Ecuador y el Polo hay una diferencia térmica de $50^{\circ} \mathrm{C}$. Hace 65 millones de años, en el Jurásico, la temperatura era muy superior a la actual y la diferencia térmica entre el Ecuador y el Polo era de unos pocos grados. Todo el planeta tenía un clima tropical. Los geólogos creen que la Tierra experimentó un calentamiento global durante ese Jurásico inferior, con elevaciones medias de temperatura que alcanzaron los $5^{\circ} \mathrm{C}$, provocando que se acelerase la erosión de las rocas hasta en un $400 \%$, un proceso en el que tardaron 150,000 años en volver a los valores normales de $\mathrm{CO}_{2}$. Posteriormente se produjo también otro episodio de calentamiento global conocido como Máximo Térmico del Paleoceno-Eoceno.

Desde hace unos dos millones de años, la Tierra ha sufrido glaciaciones en las que gran parte de Norteamérica, Europa y el norte de Asia han quedado cubiertas de hielo, hielo que luego desapareció dando lugar al período interglacial en el que vivimos. El proceso se repite cada cien mil años aproximadamente. La última época glacial terminó hace unos quince mil años, y dio lugar a un cambio fundamental en los hábitos del hombre, que desarrolló el conocimiento necesario para domesticar plantas y animales. La mejora de las condiciones térmicas facilitó al paso del paleolítico al neolítico hace unos diez mil años".

Como se ve, el $\mathrm{CO}_{2}$ ha jugado siempre un papel importante $\mathrm{n}$ la historia del clima. Tal vez el mecanismo de compensación funcione en un plazo de cientos de años, cuando el Sol entre en un nuevo mínimo. En un plazo de miles de años tal vez se reduzca la temperatura, desencadenándose la próxima glaciación. Todo es cuestión de "tal vez". Esa es la incertidumbre humana. Pero realmente, en estos enormes y complejísimos procesos naturales, pretender que la intervención del 
hombre es importante y puede cambiar los rumbos de la dinámica natural, es, realmente, un contrasentido, producto de la falta de humildad y prudencia del género humano, de su acentuado antropocentrismo, de su falta de conocimiento y comprensión de la realidad, y también, de los intereses del dinero y del poder que se dan a lo largo de la superficie terrestre entre unas sociedades y otras.

En este punto, quisiera referirme un asunto que es de particular interés para la propia realidad de nuestro país: Se sabe que los océanos del mundo absorben aproximadamente un tercio de los incrementos del $\mathrm{CO}_{2}$ atmosférico, lo que hace que constituyan el sumidero más importante de carbono. El gas se incorpora bien como gas disuelto o en los restos de diminutas creaturas marinas que caen al fondo para convertirse en creta o en piedra caliza. La escala temporal de ambos procesos es diferente, y tiene su origen en el ciclo del carbono. La incorporación de dicho gas al océano plantea problemas ecológicos por la acidificación al mismo. En El Salvador, las aguas subterráneas, (pozos, por ejemplo), se mantienen siempre en el equilibrio bicarbonato. Todo el equilibrio $\mathrm{CO}_{2}-\mathrm{CO}_{3} \mathrm{H}-\mathrm{CO}_{3}-\mathrm{OH}$ se sitúa en la región del bicarbonato. Este es un fenómeno que se origina en la presencia del $\mathrm{CO}_{2}$ en el agua: Entre los componentes del agua lluvia se encuentra precisamente el $\mathrm{CO}_{2}$, que va reaccionando con algunas sales calcáreas presentes en las rocas transformándose en Bicarbonato de Calcio:

$$
\mathrm{CO}_{3} \mathrm{Ca}+\mathrm{CO}_{2}+\mathrm{H}_{2} \mathrm{O}=\left(\mathrm{CO}_{3} \mathrm{H}\right)_{2} \mathrm{Ca}
$$

La disolución calcárea con el agua crea cavidades subterráneas y grutas. Este fenómeno, que se conoce como “Carsismo", es típico en el país, y origina la presencia de los bicarbonatos en nuestras aguas subterráneas, con una alta proporción de consumo del $\mathrm{CO}_{2}$ atmosférico arrastrado en el agua lluvia. En las grutas abandonadas al curso del agua, la humedad condensa sobre las rocas, y, gota a gota, libera Bicarbonato de Calcio, el cual, acumulándose bajo la forma de agregados de cristales de Calcita da vida a figuras como las estalactitas, que penden del techo, y las estalagmitas, que se alzan del suelo.

Este fenómeno del “carsismo" es un regulador natural del $\mathrm{CO}_{2}$ en la atmósfera, mucho mayor que cualquier esfuerzo regulador artificial que pudiera provocar el hombre. De allí la importancia de provocar una mayor infiltración del agua lluvia en nuestros suelos, ahora muy escasa debido al incremento de la escorrentía provocada por la acción del hombre con su sistema de "desarrollo" y "progreso" en las ciudades. De esto, los propulsores del "cambio climático" y del "calentamiento global" no dicen nada.

\section{El cambio climático}

En 1974, los químicos F. Sherwood Rowland y Mario Molina alertaron sobre el uso de los llamados Clorofluorocarbonos, (Freón ${ }^{-11}$ y Freón ${ }^{-12}$ ), diciendo que no se desintegraban rápidamente en la atmósfera baja, y que, "de alguna mane- 
ra", llegarían hasta la estratósfera, dando origen a su famosa teoría del "Ciclo catalítico del Cloro", también conocida como la "Teoría química de la destrucción de la capa de ozono". Se suponía que tales compuestos, liberados en la Tierra, al igual que cualquier otro gas más liviano que el aire, tenían que ser dispersados por los vientos a toda la atmósfera independientemente del lugar en el que fueran liberados; en marcha lenta, pero segura, las corrientes ecuatoriales ascendentes deberían transportarlos hacia la estratósfera, hacia un inexorable encuentro fotoquímico con la radiación ultravioleta solar más energética, ante la cual son inestables. Como consecuencia de la reacción, se liberaba cloro, estimando que cada átomo de cloro liberado sería capaz de desarrollar una reacción en cadena que destruía 100,000 moléculas de ozono. Molina y Rowland escribieron sus famosas ecuaciones, las cuales fueron consideradas incluso como unas de las diez más famosas de la ciencia actual, obteniendo por ello el premio Nobel. Tales ecuaciones, en forma simple, podrían escribirse así:

$$
\begin{gathered}
\mathrm{Cl}_{3} \mathrm{CF}+\mathrm{hv}(\lambda<230 \mathrm{~nm}) \rightarrow \mathrm{Cl}_{2} \mathrm{CF}+\mathrm{Cl}^{\prime} \\
\mathrm{Cl}^{\prime}+\mathrm{O}_{3} \rightarrow \mathrm{ClO}+\mathrm{O}_{2} \\
\mathrm{ClO}+\mathrm{O}^{\prime} \rightarrow \mathrm{O}_{2}+\mathrm{Cl}^{\prime} \\
\mathrm{NO}_{2}+\mathrm{ClO} \rightarrow \mathrm{ClNO}_{2}
\end{gathered}
$$

Como se ve, este ciclo catalítico puede ser bloqueado por el $\mathrm{NO}_{2}$, uno de los tantos gases atmosféricos, provocando el secuestro de ClO. Esta es la conocida "Reacción de Interferencia", ya que bloquea la degradación del ozono producida por los derivados de los clorofluorocarbonos.

Algunas observaciones han sido hechas a esta teoría, tan difundida en la actualidad, y base soporte de la otra teoría del cambio climático:

En primer lugar, los clorofluorocarbonos no son más livianos que el aire. El más ligero de los freones Freón ${ }^{-12}$, pesa 4.10 veces más que el aire, y el Freón ${ }^{-11}$, es 4.66 veces más denso que la atmósfera. Estos gases, al ser liberados, descienden a niveles inferiores. Por lo tanto, no suben a la estratósfera, razón por la cual no han podido encontrarse moléculas de los mismos en las muestras obtenidas en dicha estratósfera, en cantidades suficientes como para tener alguna importancia.

En segundo lugar, para que los clorofluorocarbonos puedan liberar sus átomos de cloro, deben ser atacados por radiación UV de menos de $190 \mathrm{~nm}$ de longitud de onda, radiación que sólo se encuentra por encima de los 40 kilómetros de altura.

Contrario a lo que sostienen algunos medios científicos, como por ejemplo el Ozono trends panel, de que la capa de ozono sobre los EUA y Europa se encuentra teniendo una disminución del orden del $3 \%$, muchos trabajos científicos afir- 
man que se está dando una disminución de la radiación UV que llega a la Tierra, o que, al menos, no se registran aumentos en dicha radiación.

Cuando apareció el famoso agujero de ozono en la Antártida, simultáneamente apareció también el agujero de los óxidos de nitrógeno. Comprobadamente, ambos agujeros obedecen a las mismas causas, fenómenos físicos naturales al final de los inviernos antárticos. El agujero de los óxidos de nitrógeno fue ocultado por los medios. Se acepta de manera general que tales fenómenos están asociados a lo que se conoce como Vértice Polar Sur, huracanes de hasta 400 $\mathrm{km} / \mathrm{hr}$ que forman un círculo que abarca toda la Antártida, y que impiden que nada salga hacia afuera y nada pueda entrar al mismo. Este vértice polar sur es, o pareciera ser, para decirlo así, el responsable de la disminución del ozono en la región, y de la misma manera, del agujero de los óxidos nitrosos, y del agujero del vapor de agua.

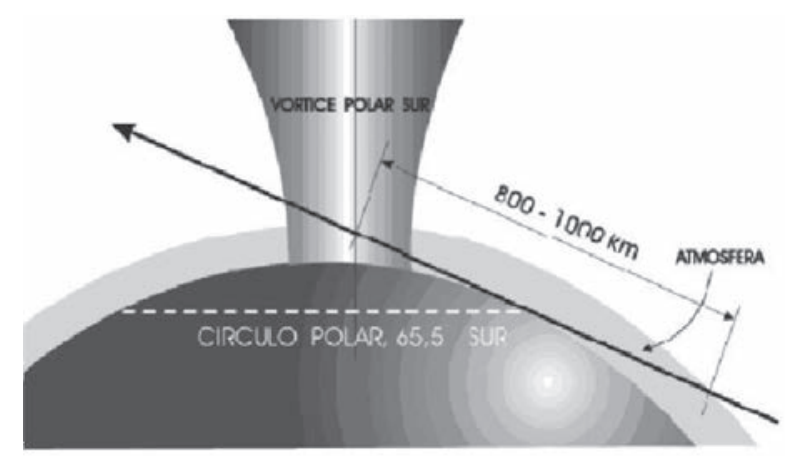

La curvatura de la Tierra y el largo camino de los rayos UV (Tomada de “Ecología, Mitos y Fraudes, El Fraude de la Capa de Ozono)

Se ha demostrado que toda la cantidad de cloro que ha sido liberada por los clorofluorocarbonos que se produjeron desde 1930 hasta hoy a la atmósfera, aun asumiendo que hayan sido liberados simultáneamente, producirían un efecto imperceptible sobre la misma, y ridículamente insignificante cuando se la compara con el cloro que la naturaleza lanza anualmente a la atmósfera. Se calcula que la producción anual de clorofluorocarbonos se eleva a unas 1,100,000 toneladas.; de estas, se liberan a la atmósfera unas 7,500 toneladas; el resto queda dentro de los aparatos de refrigeración o almacenado. La biota oceánica libera, por el contrario, unos 5 millones de toneladas de cloro; la quema de bosques, selvas y rastrojos agregan otros 8 millones más; los volcanes del planeta agregan 36 millones; y el cloro aportado por los océanos es del orden de los 600 millones de toneladas. Es decir, la cantidad de cloro de origen natural es unas 80,000 veces mayor que la que presumiblemente liberan los clorofluorocarbonos. Mediciones indican que la existencia de clorofluorocarbonos en la estratósfera es casi nula, unas $0.1 \mathrm{ppb}$, y en alturas en las cuales la radiación UV no tiene la energía necesaria para provocar la liberación de sus átomos de cloro. 


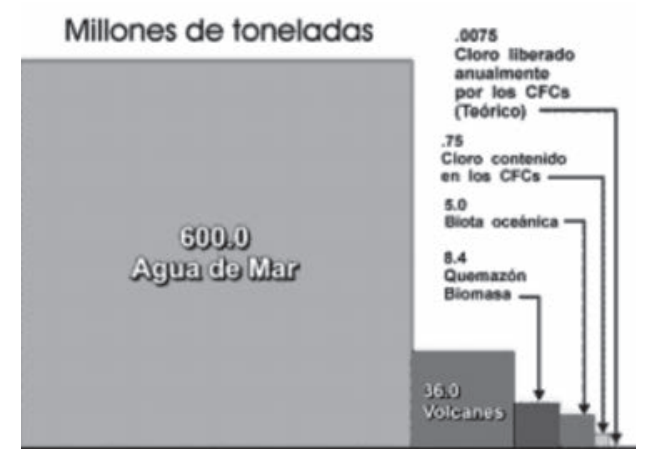

Fuentes atmosféricas de Cloro, Millones de toneladas anuales.

Tomado de "The holes in the ozone scare"

Maduro y Schauerhammer, 21st Century Science Associates, Editores, Washington, D. C.

La crítica a la teoría de que los clorofluorocarbonos son los causantes de la disminución de la capa de ozono ha sido tan sostenida técnica y científicamente, que ello hizo que los promotores de la teoría del cambio climático se desviaran entonces hacia otra posible causa, las emisiones de dióxido de carbono, $\mathrm{CO}_{2}, \mathrm{y}$ de otros gases de invernadero. De estos gases de invernadero, conocidos como "gas serra", $\left(\mathrm{CO}_{2}\right.$, anhídrido carbónico, $\mathrm{CH}_{4}$, metano, $\mathrm{N}_{2} \mathrm{O}$, óxidos de nitrógeno, CFCs, clorofluorocarbonos, HFCs, hidrofluorocarbonos, y $\mathrm{SF}_{6}$, exafluoruro de azufre), el primero es el que ha generado más atención debido a su abundancia. Su "potencial de calentamiento" se toma como la unidad, y en relación con este, los potenciales de los otros gases son: 23 para el metano, 296 para los óxidos de nitrógeno, entre 6,000 y 14,000 para los clorofluorocarbonos, entre 12 y 12,000 para los hidrofluorocarbonos, y 22,000 para el exafluoruro de azufre. Sus ciclos de vida atmosférica son, en su orden: 100 a 1,000 años para el $\mathrm{CO}_{2}, 12$ años para el metano, 114 años para los óxidos de nitrógeno, entre 45 y 1,700 años para los clorofluorocarbonos, entre 3 y 260 años para los hidrofluorocarbonos, y 3,200 años para el exafluoruro de azufre. Los defensores del cambio climático sostienen que hay un incremento en los valores del anhídrido carbónico en la atmósfera, valores que han aumentado, en unos dos siglos y medio, desde 278 ppm hasta 380 ppm en la actualidad. Este incremento, unos 1.5 a 2 ppm por año últimamente, ha servido como justificación para tratar de confirmar el efecto invernadero y su consecuencia, el cambio climático. Los otros gases serra han tenido incrementos realmente despreciables. Pero tal incremento en la concentración de $\mathrm{CO}_{2}$ en la atmósfera de la Tierra no es suficiente para justificar, científicamente, que debido a ello se puedan dar incrementos en su temperatura como los que se asumen. Causas que salen del efecto antrópico tienen mayor significación en tales aumentos en la temperatura, siendo estos, en realidad, mucho menores que los que asumen los defensores y propulsores del cambio climático. 
Hay que hacer ver que la "huella del carbono" que provocan los países tiene diferencias muy grandes entre unos y otros, y esto es importante para señalar las responsabilidades de cada quien. Como ejemplo, la huella del carbono de los Estados Unidos de Norteamérica es del orden de los 20,000 kilogramos por persona por año; un habitante del Reino Unido contribuye con una huella del carbono de 9,500 kilogramos por persona por año; la China y la India son responsables de huellas del carbono de 3,200 y 1,200 kilogramos por persona por año, mientras que un habitante de Tanzania sólo contribuye al calentamiento con 100 kilogramos por persona por año. Los datos anteriores muestran taxativamente las profundas iniquidades y desigualdades que hay en el mundo.

Algunas cuestiones que los defensores del cambio climático no han podido explicar, se exponen a continuación como simples efectos:

a) El efecto negativo de retorno que las nubes producen sobre el mismo, y que atenúan sus consecuencias.

b) Los modelos climáticos fallan al intentar predecir el clima.

c) Los modelos climáticos fallan al intentar reconstruir o predecir la variabilidad natural.

d) Los modelos climáticos no pueden reconstruir el pasado climático.

e) El hecho de la poca relación entre los rayos cósmicos y los efectos climáticos.

Contra-argumentos en contra del probable efecto antrópico sobre el cambio climático pueden también ser expuestos:

a) Los datos sobre el núcleo glacial sugieren que el $\mathrm{CO}_{2}$ atmosférico responde a la temperatura global, por lo que no puede ser el causante de los cambios globales de temperatura.

b) Muchos datos que muestran el llamado "calentamiento global" han sido corregidos o torcidos para poder alcanzar los resultados deseados.

c) Cambios recientes en las temperaturas globales se deben a cambios en el Sol.

d) Hay indicios que muestran una reducción en los niveles de calentamiento global.

En cuanto a esto del manejo de los datos para alcanzar los resultados deseados, cada día se presentan más evidencias que han llevado a la desconfianza con que tales informaciones son vistas. Algunos ejemplos podrían considerarse:

El pretendido deshielo de la capa de hielo de Groenlandia sostenido por Times Atlas (The Times Comprehensive Atlas of the World), que indicaba que tal deshielo estaba convirtiendo a Groenlandia en "tierra verde", que se ha demostrado ser incorrecta, y que dicha capa de hielo se mantiene, sosteniendo sus aproximadamente 2.9 millones de kilómetros cúbicos, y una pérdida del orden de 200 kilómetros cúbicos por año, $\mathbf{0 . 1} \%$ de tal volumen en un período de doce años). Tal tasa de deshielo significa que se necesitará un período del 
orden de 14,500 años para el deshielo total, período para el cual la próxima glaciación habrá ya aparecido.

La afirmación de que el incremento en el nivel del mar por efecto del cambio climático haría que las islas Maldivias estarían sumergidas dentro de 50 años, contrario al hecho real de que dicho nivel ha descendido un poco en la época de los años 70' del siglo anterior, manteniéndose dichos niveles por los últimos treinta años

Hay, indudablemente, argumentos en pro y en contra del cambio climático, y diferentes modelos de soporte en cada caso. Pero ninguno tiene la suficiente rigurosidad científica e incluso la necesaria aceptación de la comunidad científica como para se aceptados. Como afirman la ciencia, "Diferentes modelos llevan a diferentes resultados". Luego, ¿por qué asumir y arrogarse una completa certeza por parte de los defensores de este fenómeno natural, y considerarlo algo dado y no discutible?

No es el objeto aquí enfocar detalladamente esta confrontación entre seguidores y críticos de tal teoría del cambio climático, pero aun asumiendo que este se esté dando efectivamente sobre la Tierra, lo cual no es nuevo en el tiempo cósmico y en el tiempo terrestre, tendría como causa principal la propia dinámica del planeta para mantener su equilibrio, y su relación con la dinámica del cosmos mismo; y aún, agregando a ello que el efecto antrópico en dicho cambio sea real, este es tan pequeño que no debería transformarse en un fin en sí mismo, como tratan de hacerlo sus defensores. Finalmente, además, el efecto antrópico no puede considerarse como un asunto puramente científico, sino que este tiene causas que lo provocan, y que se sitúan en las esferas económicas, sociopolíticas, geopolíticas, legales y sanitarias, sólo para citar algunas. No es posible hacer una consideración del asunto del cambio climático aisladamente, sin entrar en la consideración de las causas que lo provocan, que son, como decimos, originadas en el sistema de desarrollo económico-social del mundo actual.

Hay que decir también que el llamado efecto invernadero, causado por los también llamados gases serra, es un efecto, (Efecto Serra) necesario para la Tierra. Sin él, la Tierra sería unos $35{ }^{\circ} \mathrm{C}$ más fría que actualmente, haciendo que la temperatura promedio en los trópicos fuera de unos - $10{ }^{\circ} \mathrm{C}$. Es decir, la Tierra es un ser vivo, es un ser dinámico, y su naturaleza es tan inmensamente complicada que es imposible para el hombre poder desentrañar sus complejos mecanismos. ¿Cómo poder pensar que Dios, en su Creación, pueda haber precisamente creado una naturaleza muerta? No debemos negar que el hombre está contribuyendo con su negativa conducta a la depredación del ambiente y conduciendo a algunas regiones al desastre ecológico; pero esto es un efecto, repetimos, del sistema, y la solución es, no equivocadamente enfrentar el llamado cambio climático como un fenómeno aislado y monocausal, sino 
enfrentar las causas que lo producen, que se sitúan en el injusto e insoportable sistema actual de desarrollo de la humanidad. Hay que dejar en paz a la naturaleza, y respetarla como Creación que es de Dios; ella sabrá entonces reaccionar adecuadamente cuando sea necesario.

Unas cortas consideraciones a otro efecto que sabe asociarse con el cambio climático: El llamado calentamiento global. La clave aquí es definir lo que se entiende como global. Si se entiende lo universal, tal teoría es de suyo inaceptable: Contradice la segunda ley de la termodinámica, que indica que aunque la energía universal se conserva y sólo se transforma, como señala la primera ley, la entropía, por el contrario, aumenta constante e irreversiblemente siguiendo la flecha del tiempo, lo cual indica que el universo se está enfriando también irreversiblemente, (todos los fenómenos naturales son irreversibles, y no ideales), hasta que se llegue a su estado final de equilibrio, que no es otra cosa que su muerte térmica. Si el término global se refiere a la Tierra, los datos muestran que en inmensas regiones se está experimentando un descenso de temperatura. Si algo en algún lado se calienta, algo en otro lado se deberá enfriar. A partir de 1880 , la temperatura promedio global ha aumentado $0.8^{\circ} \mathrm{C}$, incrementando la temperatura en los océanos, su nivel en alrededor de $20 \mathrm{~cm}$, y provocando una declinación del hielo marino en el Ártico en el orden de un $40 \%$. Esto está lejos de las estimaciones catastróficas que se saben expresar en cuanto a los efectos del cambio climático, que hablan de aumentos de la temperatura promedio en la Tierra del orden de entre 2.8 y $5.6^{\circ} \mathrm{C}$ en los próximos 85 años, lo cual provocaría, según los economistas macroeconómicos mecanicistas, disminuciones de hasta un $20 \%$ del producto interno bruto del planeta; en nuestro país se ha afirmado que el cambio climático podría ocasionar invasiones del océano que pudieran llegar hasta a cubrir lugares como Zaragoza, e incrementos de hasta 2 a $5^{\circ} \mathrm{C}$ en los próximos 25 años. Estas visiones apocalípticas nublan una visión correcta del asunto.

Tozzi, Mario, en su obra "Uomo e Natura, quale futuro possibile?", (Mario Tozzi, Uomo e natural, quale futuro posible?, Istituto Geografico DeAgostini, Novara, Italia, 2009), hablando del clima, señala ciclos de períodos sucesivos de enfriamiento-calentamiento que corren desde 5,000 años antes de Cristo hasta la actualidad. Señala Tozzi que desde 5,000 años a.C. hasta el 2,500 a.C. hubo un período de creciente calentamiento, que comenzó a declinar y continuó en esa tendencia hasta el año 1,000 a.C. A partir de esta fecha, períodos de enfriamiento y calentamiento han venido sucediéndose, siendo a partir del año 1,200 que se ha dado un largo período de enfriamiento que ha durado hasta aproximadamente el año 2,000. De nuevo, a partir de dicho año, un nuevo calentamiento terrestre es previsible. Tales períodos pueden establecerse, con suficiente aproximación, en la forma siguiente. 
Año 5,000 a.C. hasta año 3,500 a.C. = Calentamiento creciente

Año 3,500 a.C. hasta año 1,000 a.C. = Calentamiento decreciente

Año 1,000 a.C. hasta año 400 a.C. = Enfriamiento progresivo

Año 400 a.C. hasta año 200 a.C. = Enfriamiento decreciente

Año 200 a.C. hasta año cero = Calentamiento creciente

Año cero hasta año 100 d.C. = Calentamiento decreciente

Año 100 hasta año $400=$ Enfriamiento creciente

Año 400 hasta año 600 = Enfriamiento decreciente

Año 600 hasta año 900 = Calentamiento creciente

Año 900 hasta 1,200 = Calentamiento decreciente

Año 1,200 hasta año 1,500 = Enfriamiento creciente

Año 1,500 hasta año 2,000 = Enfriamiento decreciente

De acuerdo con tal tendencia, es de esperar un nuevo ciclo de calentamiento creciente, lo cual no significa sino la confirmación de esa dinámica terrestre que le permite al planeta adaptarse hacia condiciones que le lleven al equilibrio. Sería aceptable pensar que esta vez, la contribución del hombre a dicho calentamiento puede ser mayor, pero ello estará siempre lejos de asumir posiciones catastróficas para la vida en la Tierra.

\section{3. ¿El Apocalipsis? ¿La Catástrofe Global?}

Muy a menudo, y con mucha insistencia, los propulsores del cambio climático proyectan una visión sombría en cuanto a las consecuencias que este fenómeno natural tendría sobre la Tierra y sobre la humanidad. El panorama que plantean es, realmente, apocalíptico, aterrador. Y algunos organismos, particularmente una "comunidad de científicos" muy poco conocida por su obra de investigación y desarrollo, que así se ha autonombrado, se erige como la expresión incontrovertible de tal realidad, prediciendo lo que ocurrirá si no se combate, bajo argumentos a su justa conveniencia, dicha realidad. Señalo algunos: El llamado "Grupo Intergubernamental de Expertos sobre el Cambio Climático de Naciones Unidas", IPCC, que a la fecha ha publicado cuatro "informes de síntesis", que por cierto se contradicen los unos a los otros. Este grupo, dos mil quinientos "científicos" procedentes de diversas disciplinas y campos de la ciencia de más de ciento treinta naciones, en su último informe ha afirmado que "el calentamiento global inducido por los seres humanos... representa una amenaza para los ecosistemas y especies de los que dependemos para nuestra propia subsistencia". Haciendo uso de las variaciones estadísticas de los llamados "gases serra", que van al aumento, (particularmente de los famosos 280 a $380 \mathrm{ppm}$ de $\mathrm{CO}_{2}$ ), ha pedido a los humanos, mediante un mensaje de su Presidente, Rajendra Kumar Pacharuri, por cierto, premio Nobel de la Paz en 2007, que reduzcan su consumo de carne como primer paso para combatir el calentamiento global. Este sería un buen mensaje para los Estados Unidos de Norteamérica, que consumen aproximadamente el $36 \%$ de la energía global 
y el $65 \%$ de la electricidad, emitiendo un $30 \%$ de los gases de invernadero a la atmósfera.

La ONU, a través de la FAO, ha afirmado que la cría moderna de animales de granja, y especialmente de ganado vacuno, produce enormes cantidades de Metano, Dióxido de Carbono y Óxidos Nitrosos, lo cual lo ha llevado a ser la segunda causa del calentamiento global, después sólo del consumo energético de los edificios. Dice este informe que el ganado produce el $18 \%$ de los gases de invernadero. (Organización de las Naciones Unidas para la Agricultura y la Alimentación, FAO, “Livestock's Long Shadow: Environmental Issues and Options" 2006).

Afirma el IPCC que de doblarse la cantidad de $\mathrm{CO}_{2}$ en la atmósfera terrestre, la superficie de la Tierra se calentará entre 2 y $4.5^{\circ} \mathrm{C}$, y probablemente, $3{ }^{\circ} \mathrm{C}$. Algunos "científicos" afirman que este valor es bajo, y que bien podría llegar a ser de $4.5{ }^{\circ} \mathrm{C}$, "según algunos modelos de predicción utilizados". (IPCC, 2 de febrero de 2007, “Climate Change 2007”, The Phisical Science Basis).

En un trabajo de "Computación Distributiva para la Creación de un Modelo del Cambio Climático", de la Universidad de Oxford Myles Allen y el Hadley Center for Climatic Prediction and Research, en el que utilizaron noventa mil ordenadores personales y ejecutaron más de dos mil simulaciones diferentes sobre el futuro del clima terrestre, se concluyó, de forma muy controvertida por cierto, que el incremento en la temperatura en la Tierra estaría entre los 4.5 y los 11.5 ${ }^{\circ} \mathrm{C}$ para finales del siglo. Esto último haría imposible toda forma de vida sobre la Tierra. (D. A. Stainforth \& otros, "Uncertainty in Predictions of the Climate Response to Rising Leves of Greenhouse gases” Nature, vol. 433, n²7, 2005.

Otro "grupo de expertos" sabe afirmar que "existe la amenaza de extinguir entre una quinta parte y hasta el $70 \%$ de todas las especies catalogadas hasta el momento". (Lenny Bemstein, “Climate Change 2007: Synthesis Report”. IPCC).

En Costa Rica, un "Grupo de Científicos" ha registrado un continuo declive en la tasa de crecimiento de los árboles de la selva tropical a medida que la temperatura de la superficie ha ido aumentando progresivamente. "Los árboles tropicales se ven sometidos a un estrés cada vez mayor debido a las temperaturas nocturnas cada vez más elevadas", dicen, y por ello, los árboles se obligan a respirar más y a liberar más $\mathrm{CO}_{2}$. Este "grupo de científicos", "se encuentra muy preocupado". (Tim Beardsley, "In the heat of the night", Scientific American, vol. $278, \mathrm{n}^{\circ} 4$, octubre de 1998).

Peter Cox, de la Oficina de Meteorología del Reino Unido, afirma que en las próximas décadas “podríamos ser testigos de una acronecrosis masiva del Amazonas como resultado del aumento $\mathrm{d}$ los niveles del estrés provocado por el calor y la liberación de miles de millones de toneladas de $\mathrm{CO}_{2}$ a la atmósfera", 
lo que podría provocar "una subida adicional de la temperatura de entre 6 y 8 ${ }^{\circ} \mathrm{C}$ en el transcurso de un siglo. (Fred Pierce, "Violent Future", New Scientist, 21 de julio de 2001).

Y un informe al respecto de las Naciones Unidas, para rematar, afirma ya definitivamente que "el cambio climático afectará fundamentalmente al ciclo hidrológico de la Tierra”,... lo cual levará a la destrucción de los ecosistemas terrestres".

Los tonos del desastre son muy variados y también su intensidad. "Combatir" la producción de gases serra significa desde abandonar el uso de fertilizantes hasta modificar los diseños de los interruptores eléctricos, del calzado deportivo y de las pelotas de tenis, debido a sus contenidos de Exafluoruro de Azufre. Mark Lynas, en su libro "Carbon Counter" (Mark Lynas, Carbon Counter", Collins Gem, Harper Collins Publisher, UK, 2007), establece los “efectos" de los incrementos de la temperatura en la superficie de la Tierra, desde $1{ }^{\circ} \mathrm{C}$ hasta $6{ }^{\circ} \mathrm{C}$. Estos "efectos" son muy singulares, e invitan al abandono de la idea de vida en el planeta, buscando alternativas de éxodo masivo. Dice Lynas que un incremento de un grado en dicha temperatura haría que los desiertos invadan las planicies altas de los Estados Unidos, se pierda toda la capa de hielo que cubre los picos del monte Kilimanjaro, se pierdan las corrientes del golfo, e incluso que las naciones islandesas se sumerjan en el mar. Ya un incremento de dos grados centígrados significaría que los osos polares, las focas y otros mamíferos dependientes de los ambientes polares se extingan en el Ártico, a medida que el hielo desaparezca, y además, que un tercio de las especies animales sobre la Tierra desaparezcan. Tres grados centígrados de incremento de la temperatura terrestre provocarían que el desierto de Kalahari se extienda sobre Botswana, engullendo su capital y cubriéndola de dunas de arena, el fenómeno del Niño se volvería permanente causando caos en el mundo, el ecosistema del Amazonas colapse en una conflagración de fuego y destrucción, los huracanes destruyan los trópicos, y el Río Indio se seque. Continúa Lynas con un incremento de cuatro grados centígrados, con lo que el Río Nilo sería inundado por el mar, colapse el hielo del Antártico Oeste, el sur de Europa, España y Portugal principalmente, se convierta en un desierto similar al Sahara, todos los glaciares de los Alpes desaparezcan, y el Permafost de Siberia se funda, liberando billones de toneladas de Metano y de Dióxido de Carbono. Con un incremento de $5{ }^{\circ} \mathrm{C}$, aparece la posibilidad de un colapso total de la humanidad, hidratos de Metano se liberan desde el fondo de los océanos, provocando tsunamis en las costas y haciendo ya indetenible el calentamiento global. Al fin, Lynas arriba a los famosos seis grados centígrados de incremento de la superficie terrestre: Este es el escenario de la extinción total masiva, tormentas de fuego se dan sobre el planeta, y los mares se vuelven anóxicos liberando fantásticas cantidades de Sulfuro de Hidrógeno, $\mathrm{SH} 2$. Estas predicciones, que Lynas confirma en "Carbon Counter", ya habían sido expuestas previamente en su libro "Six Degrees", (Mark Lynas, Six Degrees, fourth state, 2007). Debe decirse que Mark Lynas reconoce que el efecto de 
la fragilidad del ambiente terrestre debe ser evitado, que hay iniquidades en el efecto que obre tal ambiente producen unas sociedades y otras, y que es necesario corregir tales inequidades. Tambíén, Lynas propone un método muy efectivo para el conteo del carbón que produce cada persona, cada comunidad, cada pueblo, su “Carbon Counter Method”, método muy simple de ejecutar.

¿A qué lleva todo lo anterior? ¿Cuál es el mensaje? ¡Y hay más! Cada día, decenas y decenas de nuevos "estudios" e "informes" de estos "grupos de científicos", muy bien apoyados por estos organismos supranacionales como la ONU, permean las mentes de la humanidad, orientándolas hacia preocuparse por un problema que es, en sí, un pseudoproblema, y desviando la atención hacia los grandes problemas que realmente le abaten. Insistiendo en sus "modelos predictivos", e ignorando que la ciencia misma ha demostrado que tales modelos siempre fallan en la predicción del clima, pronuncian un discurso realmente desgarrador sobre el futuro de la Tierra, de la vida sobre ella, y particularmente de la humanidad.

Al margen, yo no he escuchado que dentro de estos "grupos de científicos" se encuentren algunos del nivel y del reconocimiento de Hawking, Penrose, Mlodinov, Prigogine, Jamer, Barrow, Montalcini, Bergia, etc.

No puede, pues, calificarse de otra manera sino de catastrófica y apocalíptica, la situación que plantean los propulsores de esta idea del "Cambio Climático" y del "Calentamiento Global". Afortunadamente, la naturaleza no hace caso de tales novedades, y sigue su curso, con su dinámica inentendible para el hombre, acomodando los sistemas a las situaciones y manteniendo ese equilibrio vital que permite que la vida continúe. John D. Barrow, un calificado científico reconocido a nivel mundial, profesor de matemáticas en la Universidad de Cambidge, UK, en su famoso libro “The Constants of Nature”, (John D. Barrow, "The Constants of Nature, from alpha to omega", Pantheon Books, New York, US, 2002), actuando con la prudencia y la sabiduría que sabe distinguir a los verdaderos científicos, cuando habla de los cambios en la vida, y refiriéndose a las intervenciones eternas en la evolución de la Tierra, (movimientos de los cometas y de los asteroides, influencias gravitacionales de La Luna y de Júpiter sobre todo, etc.), nos dice algunas cosas que aclaran la visión que debe tenerse de la dinámica universal y terrestre: Dice Harrow: "Las intervenciones externas sobre la evolución de la Tierra tienen otra curiosa cara: Ciertamente pueden producir una extinción global, y retroceder en la evolución en su complejidad por millones de años. Pero, siendo moderados, ellos pueden provocar un efecto positivo de aceleración de la evolución en las formas de vida inteligente. Cuando los dinosaurios se extinguieron por el impacto de un enorme meteorito o de un cometa sobre la superficie de la Tierra en la península de Yucatán hace 65 millones de años al final de la era mesozoica, la Tierra fue rescatada de una muerte final de su evolución. Los dinosaurios pareciera que habían desarrollado a lo largo de su evolución un sistema que desarrollaba su tamaño 
físico sin un desarrollo paralelo y correspondiente del tamaño de su cerebro. Al desaparecer, junto con la mayoría de otras formas de vida de ese entonces, se abrió el espacio para el aparecimiento de los mamíferos y para la apertura de nichos de competencia por los recursos naturales. Ello provocó una rápida aceleración del desarrollo de la diversidad". Esta fue una oportunidad, la oportunidad, del hombre, para su aparecimiento y desarrollo. Ahora, el antropocentrismo nos lleva equivocadamente a pensar que estamos en el punto Omega de la evolución; pero la naturaleza se encargará seguramente de disipar tal cerrada y estrecha visión. Richard Gott, en sus "Predicciones en el Día de Nueva York", 2000, dice que el homo sapiens, (200,000 años de edad) sobrevivirá probablemente más de 51,000 años, pero menos de 7.8 millones de años. El hombre no será eterno. ¿Cuál es entonces la preocupación? El hombre, en la historia cósmica, no es una criatura especial, pero en la historia de la Tierra, afirma Gott, sí es un Ser confidente, y su vida se asemejará en el tiempo a la del planeta. No hay, continúa, razón para confinar este argumento a algún evento cataclísmico que lleve a la extinción de la vida humana. (Richard Gott's Predictions on New York's Day, 2000, The Wall Street Journal).

\section{Hacia un posicionamiento adecuado ante el cambio climático y el Calentamiento global}

\section{Un posicionamiento correcto en relación a la posibilidad de un "Cambio Climático"}

Por supuesto que no debe adoptarse una posición absoluta de negativa ante la posibilidad de que la Tierra esté experimentando un "cambio climático". Este es perfectamente posible, y la historia de la Tierra lo comprueba.

Lo que debe decirse es que el "cambio climático", si efectivamente se está dando, es efecto de la propia dinámica del planeta, conectada a su vez con la misma dinámica universal; que obedece a variables tanto internas como externas de dichas dinámicas que se sitúan fuera de la capacidad del hombre; y que el efecto del hombre sobre su aparición es realmente insignificante.

La posición debiera ser entonces admitir que el efecto antrópico sobre dicho fenómeno es realmente insignificante, respetar a la naturaleza en su propia dinámica, y no pretender cambiarla con acciones que lejos de ayudar pudieran seguramente provocar efectos negativos, no sobre la naturaleza misma, sino sobre él mismo.

\section{La posición del país}

El 23 de marzo de 2011, el Ministerio de Medio Ambiente y Recursos Naturales presentó ante el Consejo de Ministros del Gobierno Central, un "Borrador inicial 
para consulta inter-institucional" que denomino "Hacia una nueva política nacional del medio ambiente”. Tal Consejo debía aprobar la propuesta.

El borrador reconoce la crítica y delicada situación del ambiente nacional, reconociendo además el carácter multicausal y multisectorial del problema, y por lo tanto, la necesidad de un tratamiento integral del mismo.

Señala dos grandes objetivos para dicha política:

a. Revertir le degradación ambiental; y

b. Reducir la vulnerabilidad frente al cambio climático.

El primero de dichos objetivos es inobjetablemente necesario. Para lograr tal objetivo, considero hacer las siguientes consideraciones:

a) Todo proceso de degradación ambiental se corrige, no combatiendo sus efectos sino evitando que estos se den al eliminar sus causas. Es un principio reconocido e incluso implícito en los contenidos de la "Regla de Oro" y de las recomendaciones de la "Comisión Burtrand", que la naturaleza se corrige por ella misma y que el equilibrio natural es obtenido sin la necesidad de la intervención de cualquier efecto antrópico.

b) Esta corrección, en nuestro país, pasa simplemente por cumplir con las leyes, particularmente las ambientales, sin excepción y sin sesgo de ninguna naturaleza.

c) Tres factores son claves para lograr tal propósito:

c.1) No contaminar;

c.2) No deforestar; y

c.3) No asolvar.

d) Cumplidas las tres anteriores acciones, la solución vendrá por sí misma.

e) No hay que "reforestar"; no hay que "descontaminar"; no hay que "desazolvar". Simplemente NO hay que contaminar; NO hay que deforestar; NO hay que asolvar.

f) Aunque no hay que desatenderse de los pequeños efectos, es urgente atender con la intensidad requerida los grandes efectos degradantes que sufre el país. Señalo algunos:

f.1) Enorme ineficiencia en los procesos de combustión desarrollados en el proceso de beneficiado del café, con altos índices de contaminación y graves desperdicios de fuentes energéticas, la leña una de ellas. Este es un problema técnicamente muy fácil de corregir.

f.2) Entre 70,000 y 90,000 manzanas de cañales que se queman"programadamente" todos los años en el curso de la zafra azucarera, con un efecto gravemente adverso al equilibrio ecológico en el microsistema nacional.

f.3) Uso excesivo de empaque de naturaleza no biodegradable o poco biodegradable en los ambientes urbanos del país, (mercados, supermercados, y en general, todo tipo de comercios), con el nocivo efecto de una sobreproducción de desechos sólidos. 
f.4) Falta de separación de los desechos domésticos e industriales "en su fuente", y establecimiento de "estaciones" inadecuadas para su tratamiento, lo cual genera descomposición biológica y físicoquímica de los mismos antes del mencionado tratamiento y que se manifiestan especialmente durante su manejo y trayecto en los camiones recolectores.

En cuanto al segundo gran objetivo, "reducir la vulnerabilidad frente al cambio climático", sobre la base de lo expuesto en este trabajo, caben las siguientes consideraciones:

a) El actual “cambio climático" es un fenómeno científicamente no comprobado. Es, hasta el momento, un asunto de mera opinión, que ciertamente ha tomado alta beligerancia. Las bases científicas que tratan de respaldar tal fenómeno actual no gozan de la aceptación de la "comunidad científica", y cada día su validez se relativiza.

b) La situación ambiental de la Tierra como planeta, e incluso del universo mismo, corresponden a manifestaciones de su ciclo natural de comportamiento, en su propia dinámica. Estas se han venido dando durante toda la historia, y nunca ha podido comprobarse que ello ha afectado la vida sobre el planeta. Son manifestaciones de autoregulación del comportamiento.

c) En todo caso, aun admitiendo que estuviéramos ante la presencia de un "cambio climático", se ha demostrado que el efecto antrópico en el mismo es infinitesimalmente pequeño. Menos aun en el caso de nuestro país, en el cual, nuestra generación de "gases de invernadero", por decir algo, no significa absolutamente nada en relación con el llamado "efecto negativo sobre la capa de ozono".

d) Ni la "teoría química" ni la "teoría mecánica" han alcanzado validez en este momento.

Una posición correcta que sitúe al país en el lugar que le corresponde ante tal situación es la de exigir que las injusticias y las asimetrías mundiales en relación con la contaminación del ambiente sean eliminadas, exigiendo a los grandes depredadores ambientales que corrijan su actuación. Es un error pretender trasladar un problema de dimensiones tan grandes, y exigir su solución, a aquellas sociedades que no lo producen, y que en todo caso, contribuyen mínimamente al mismo.

Por lo tanto, de los dos grandes objetivos planteados en el documento en referencia, el esfuerzo del país debería centrarse absolutamente en el primero, "Revertir la degradación ambiental", evitando distraer recursos y esfuerzo en el segundo, "reducir la vulnerabilidad frente al cambio climático", cuyo carácter sale del ámbito posible de acción que pudiéramos tener. Centrando los esfuerzos en combatir la degradación ambiental, y yendo en ello a los factores mayores, considero que es la mejor forma de ayudar a reducir tal vulnerabilidad ante tal cambio, si es que efectivamente nos encontramos ante él. 
Es importante que el país no se confunda ante la situación. Los intereses económicos y de poder que están orientando a muchos países pobres a dedicar esfuerzos y recursos ante un problema que no es de ellos, o que lo es en una muy reducida proporción, deben ser identificados claramente, y rechazados con la misma claridad.

\section{Bibliografía}

Gerardo Amaya Duarte, S.J. “Antropocentrismo, ¿un concepto equívoco? Entretextos, 7, Universidad Iberoamericana, León, 2014.

Roger Penrose, "La mente nueva del Emperador", Consejo Nacional de Ciencia y Tecnología, Fondo de Cultura Económica, México, 1996.

Robert Clarke, "Los nuevos enigmas del universo", Alianza Editorial, El Libro de Bolsillo, segunda edición, España, 2015.

Erwin Schrodinger, "¿Qué es la Vida?", Canto, Cambridge University Press, U.K. 2010.

Stephen Hawking-Leonard Mlodinov, "The grand design”, Bantam Books, New York, 2010.

Roberto Badía Montalvo, "Civilizaciones e imperios de la antigüedad: La Helade y la Antigua Grecia", en prensa, 2015.

http:://es.wikipedia.org/wiki/Cambio clim\%C3\%Altico

Mario Tozzi, “Uomo e Natura, quale futuro possibile?", Istituto Geografico DeAgostini, Novara, Italia, 2009.

Mark Maslin, "Climate Change, a very short introduction", Oxford University Press, third edition, Great Britain, 2014.

Sergio Fracanzani, "Scienze della Terra", Memory Book, Italia, 2003.

Carlos M. Duarte, "Impactos del Calentamiento Global sobre los Ecosistemas Polares", Instituto Mediterráneo de Estudios Avanzados, Universidad de las Islas Baleares, Esporles, Mallorca, España, 2007.

Antonio Valero, Termoeconomía: El punto de encuentro de la Termodinámica, la Economía y la Ecología", CIRCE, Instituto Juan de Herrera, España, 2012.

Ministerio de Medio Ambiente y Recursos Naturales, El Salvador, C. A., "Hacia una nueva política nacional del medio ambiente", San Salvador, 23 de mayo de 2011.

J. Martín Vide, "El sistema climátic i deu afirmacons sobre el camvi climatic", Cátedra Lluis A. Santaló, UdeG, España, 2008.

El Fraude de la Capa de Ozono. 